\title{
Bioactive Coating of Titanium Surfaces with Recombinant Human $\beta$-Defensin-2 (rHußD2) May Prevent Bacterial Colonization in Orthopaedic Surgery
}

\author{
By Nadine Y. Pfeufer, Karsten Hofmann-Peiker, Mike Mühle, Patrick H. Warnke, MD, \\ Martin C. Weigel, $\mathrm{PhD}$, and Michael Kleine, $\mathrm{PhD}$ \\ Investigation performed at PLANTON GmbH, Kiel, Germany
}

\begin{abstract}
Background: A promising strategy to prevent infections around orthopaedic titanium implants is to use naturally occurring cationic antimicrobial peptides (CAMPs) such as the human $\beta$-defensin-2 as antibacterial coatings. Human antimicrobial peptides represent a part of the innate immune system and have a broad antimicrobial spectrum against bacteria, fungi, and viruses.
\end{abstract}

Methods: In the present study, titanium surfaces were functionalized by four different self-assembled monolayers (SAMs) forming methoxy silanes: (1) hexadecyltrimethoxysilane, (2) dimethoxymethyloctylsilane, (3) allyltrimethylsilane, and (4) 3-aminopropyltrimethoxysilane. In addition, calf skin type-I collagen was cross-linked to the SAM surface 3-aminopropyltrimethoxysilane by means of two different treatments: (1) N-hydroxysuccinimide and (2) glutaraldehyde. The functionalized titanium surfaces were coated with recombinant human $\beta$-defensin-2 (rHußD2), an antimicrobial peptide, and were tested for antibacterial activity against Escherichia coli. The release of rHußD2 was quantified by means of enzyme-linked immunosorbent assay (ELISA).

Results: The coating of functionalized titanium surfaces with rHußD2 was successful. Recombinant HußD2 was eluted from the titanium surfaces continuously, yielding antimicrobial activity up to several hours. Antimicrobial activity with a killing rate of $100 \%$ was observed for all functionalized titanium surfaces after two hours of incubation. The dimethoxymethyloctylsilane-functionalized titanium surface delivered $0.65 \mu \mathrm{g}$ of $\mathrm{rHu \beta D} 2$ after six hours with a $60 \%$ bacterial killing rate. The silane-functionalized surfaces exhibited a faster release of antimicrobially active rHußD2 compared with collagen modifications.

Conclusions: Natural antibiotics such as $\mathrm{rHu} \beta \mathrm{D} 2$ integrated into the metal surface of titanium implants may be a promising tool to prevent and control infections around orthopaedic implants.

Clinical Relevance: This kind of titanium surface modification may provide an alternative treatment of serious, lifethreatening infections related to prosthetic implant surgery.

$\mathrm{T}$ he insertion of titanium implants during orthopaedic surgery is a common and relatively safe procedure today. However, bacterial infections around an implant remain difficult to control. Staphylococcus aureus and several other strains of Staphylococcus are frequently associated with the colonization of orthopaedic implants and are responsible for subsequent infections. Peri-implant infections may be dependent on the microbial flora at the operative site, and hospitalacquired multi-drug-resistant bacteria play an increasing role in causing these infections ${ }^{1,2}$.

Antibiotics such as vancomycin, when covalently attached onto titanium surfaces, reduce in vitro colony formation of

Disclosure: In support of their research for or preparation of this work, one or more of the authors received, in any one year, outside funding or grants in excess of $\$ 10,000$ from the European Union, MyJoint, FP6-NEST-028861. In addition, one or more of the authors or a member of his or her immediate family received, in any one year, payments or other benefits in excess of $\$ 10,000$ or a commitment or agreement to provide such benefits from a commercial entity (PLANTON). 
The Journal of Bone \& Joint Surgery $\cdot$ Jbjs.org Volume 93-A · Number 9 - MAY 4, 2011
Bioactive Coating of Titanium Surfaces with RHußD2 May Prevent Bacterial Colonization gram-positive bacteria ${ }^{3}$, but the prophylactic use of local antibiotics during implant placement is controversial. Treatment with antibiotics may trigger allergic reactions ${ }^{4}$ and could promote the induction of multi-drug-resistant bacteria ${ }^{5,6}$. Thus, the development of surfaces and coatings that can actively kill bacteria remains a challenge. Probably the oldest and most widespread coatings are silver ions, which have been successfully applied against methicillin-resistant Staphylococcus aureus $(\text { MRSA })^{7}$. However, a drawback of this approach is the cytotoxicity of silver ions toward mammalian cells.

More recently, surface functionalizations such as adsorption, coating, or covalent binding with artificial antimicrobial peptides and several cationic, polycationic, and steroid antibiotics have been described ${ }^{9-12}$. The hydrophobic and positively charged side groups of these small molecules can interact with the microbial membrane, leading to its disintegration and the metabolic breakdown of the microbe. However, the production of such surfaces for medical use is still expensive. In addition, medical acceptability of these molecules is low because of their unknown interactions with mammalian cells. Therefore, a promising strategy to prevent infection around orthopaedic implants is the use of naturally occurring cationic antimicrobial peptides (CAMPs) for bioactive coatings.

CAMPs represent a part of the innate immune system and have a broad antimicrobial spectrum ${ }^{13}$. The cationic nature of CAMPs mainly contributes to their cell selectivity because the surface of bacterial membranes is more negatively charged than that of mammalian cells. Therefore, CAMPs exhibit a strong antimicrobial activity but no cytotoxicity to mammalian cells $^{14}$. This class of antimicrobial peptides is active even against multi-drug-resistant bacteria such as MRSA. As the mechanism of their action differs from that of classical antibiotics, the formation of resistant microbes has not been observed ${ }^{15-18}$. The CAMP used in the present in vitro study is recombinant human $\beta$-defensin-2 (rHußD2), a molecule that is expressed in human epithelial cells after stimulation by injury or different inflammatory factors ${ }^{19}$. Moreover, $\mathrm{rHu} \beta \mathrm{D} 2$ takes part in the recruitment of cells of the adaptive immune response in chemoattractant macrophages and mast cells promoting wound-healing ${ }^{20-23}$. Recombinant HußD2 exhibits antimicrobial activity against both gram-positive and gram-negative bacteria, fungi, and viruses ${ }^{24-26}$.

The purpose of the present study was to test the antimicrobial activity of $\mathrm{rHu} \beta \mathrm{D} 2$ coated on different functionalized titanium surfaces. Furthermore, the release behavior in relation to the antimicrobial properties of $\mathrm{rHu} \beta \mathrm{D} 2$ on two different collagen titanium scaffolds was investigated.

\section{Materials and Methods Titanium Pins}

ne hundred custom-designed oxidized titanium pins were used in the
present study. Cylindrical pins measuring $1 \mathrm{~mm}$ in diameter and $5 \mathrm{~mm}$ in height were made from pure titanium (ASTM Grade 4) according to ISO (International Organization for Standardization) 5832-2. The surfaces were produced by means of a sandblasting process with corundum particles, followed by a strong acid-etching procedure (a mixture of $\mathrm{HCl} / \mathrm{H}_{2} \mathrm{SO}_{4}$ ) at room temperature for several minutes. This led to fine micropits of 2 to $4 \mu \mathrm{m}$ superimposed on the sand-blasted surface.

\section{Preparation of the Titanium Surface}

Prior to surface functionalization, all of the pins underwent ultrasonic treatment (Sonorex Super 10P; Bandelin, Berlin, Germany) for ten minutes in 5-M $\mathrm{KOH}$, for ten minutes in $69 \% \mathrm{HNO}_{3}$, and finally for fifteen minutes in a 2:1 $\mathrm{H}_{2} \mathrm{SO}_{4} / \mathrm{H}_{2} \mathrm{O}_{2}$ mixture at room temperature. Titanium pins were then extensively rinsed with distilled water. Next, the pins were incubated for one hour at $65^{\circ} \mathrm{C}$ in an oxidizing solution $\left(\mathrm{NH}_{4} \mathrm{OH} / \mathrm{H}_{2} \mathrm{O}_{2} /\right.$ distilled water in a ratio of 1:1:1) and were stored for sixteen hours at $4^{\circ} \mathrm{C}$ in $70 \%$ ethanol.

\section{Functionalization of the Titanium Surface}

Prior to coating of $\mathrm{rHu} \beta \mathrm{D} 2$ on the titanium pins, the surfaces of the pins needed to be functionalized. Four different self-assembled monolayers (SAM1 through SAM4) were produced by means of direct silanization of the hydrophilized pin surfaces ${ }^{27}$. Thus, twenty titanium pins were incubated in $250 \mu \mathrm{L}$ toluene consisting of a $10 \%$ solution of hexadecyltrimethoxysilane (SAM1), dimethoxymethyloctylsilane (SAM2), or allyltrimethoxysilane (SAM3). In addition, forty pins were incubated in $250 \mu \mathrm{L}$ toluene consisting of a $10 \%$ solution of 3-aminopropyltrimethoxysilane (SAM4). Both silanization procedures were performed for twenty-four hours at room temperature. Then the pins were extensively rinsed with toluene and were dried at room temperature. Additional carboxylic acid $(\mathrm{COOH})$ groups on the SAM3 titanium pins were generated by oxidation of the $\mathrm{CH}=\mathrm{CH}_{2}$ functional group from allyltrimethoxysilane by incubation with $5 \% \mathrm{KMnO}_{4}$ acid aqueous solution and finally were washed with distilled water.

\section{Collagen Binding to the Functionalized Titanium Surface (SAM4)}

To bind collagen in a stable manner onto the functionalized titanium oxide surface, the protein fibrils were cross-linked with the 3-aminopropyltrimethoxysilane (SAM4) layer in two different ways.

First, forty SAM4 titanium pins were pre-incubated in $200-\mathrm{mM} 2-(\mathrm{N}-$ morpholino)ethane sulfonic acid (MES) ( $\mathrm{pH} 5.5)$ for one hour at room temperature. Twenty-five microliters of collagen solution from calf skin type I (0.1\%, C8919; Sigma-Aldrich, St. Louis, Missouri) were applied by pipette to the pins, and the pins were dried at room temperature. Cross-linking with $\mathrm{N}$-hydroxysuccinimide (NHS) and 1-ethyl-3-(3-dimethylaminopropyl)carbodiimide $\mathrm{HCl}$ (EDC) was performed by incubating twenty pins in a solution of 10-mM NHS and 30-mM EDC in 200-mM MES ( $\mathrm{pH}$ 5.5) for six hours at room temperature. The surface modification was referred to as SAM4::Col-NHS.

Second, the dried collagen fibrils on the SAM4 titanium pin surface were cross-linked by incubating the remaining twenty pins in a $25-\mu \mathrm{L}$ glutaraldehyde solution $(25 \%)$ for one hour at room temperature. Subsequently, the pins were rinsed in a $0.1 \% \mathrm{w} / \mathrm{v}$ bovine serum albumin (BSA) and $200-\mathrm{mM}$ phosphatebuffered saline (PBS) solution for twenty minutes, followed by incubation in 100$\mathrm{mM} \mathrm{Na} \mathrm{HPO}_{4}$ for one hour, and finally were washed in distilled water, dried in a desiccator, and stored at $4{ }^{\circ} \mathrm{C}$. The surface modification was referred to as SAM4::Col-Glu. The successful binding of collagen was monitored with a collagenspecific stain after treatment with $0.1 \% \mathrm{w} / \mathrm{v}$ DirectRed 80 in $0.5 \% \mathrm{v} / \mathrm{v}$ acetic acid. All chemicals were purchased from Sigma-Aldrich if not described otherwise.

Coating of rHußD2 to the Functionalized Titanium Surfaces Five different groups of functionalized titanium pins were produced and investigated in this study: three silanized titanium surfaces (SAM1, SAM2, SAM3) and two SAM4::collagen titanium surfaces (SAM4::Col-NHS, SAM4::Col-Glu). Recombinant human $\beta$-defensin-2 ( $\mathrm{rHu} \beta \mathrm{D} 2$ ) was produced by PLANTON (Kiel, Germany) as described previously ${ }^{25}$. Coating of this peptide was performed by directly adding $10 \mu \mathrm{L}$ of a $1 \mathrm{mg} / \mathrm{mL}$ or an $8 \mathrm{mg} / \mathrm{mL} \mathrm{rHu} \beta \mathrm{D} 2$ solution (in $0.01 \%$ acetic acid) onto the functionalized titanium surfaces. Finally, the pins were dried in a desiccator and were stored at $4^{\circ} \mathrm{C}$ prior to use.

In this way, two sets of SAM1, SAM2, and SAM3 layers were generated by coating either $10 \mu \mathrm{g}$ or $80 \mu \mathrm{g}$ of $\mathrm{rHu} \beta \mathrm{D} 2$ on each surface. The 


\begin{tabular}{|c|c|c|c|c|c|c|}
\hline & \multicolumn{6}{|c|}{ rHußD2 Controls } \\
\hline Amount of applied rHußD2 ( $\mu \mathrm{g})$ & 0 & 0.02 & 0.20 & 2.00 & 10.00 & 10.00 \\
\hline Amount of $r \mathrm{Hu} \beta \mathrm{D} 2$ determined with ELISA $\dagger(\mu \mathrm{g})$ & 0 & $0.02 \pm 0.01$ & $0.18 \pm 0.01$ & $1.70 \pm 0.14$ & $9.01 \pm 0.82$ & $8.89 \pm 0.72$ \\
\hline Antimicrobial activity, bacterial killing $\dagger(\%)$ & 0 & $14.80 \pm 2.78$ & $32.38 \pm 2.93$ & $92.80 \pm 3.91$ & 100 & 0 \\
\hline
\end{tabular}

SAM4::collagen functionalized titanium surfaces were coated with $80 \mu \mathrm{g}$ of $\mathrm{rHu} \mathrm{DD} 2$.

\section{Antibacterial Assays}

The antibacterial activity of the $\mathrm{rHu} \beta \mathrm{D} 2$-coated pins was tested by means of a microdilution assay as described recently ${ }^{27}$, but with the following modifications. Escherichia coli strain DB3.1 (Cat. No. 11782-018; Invitrogen, Carlsbad, California) was used. Escherichia coli was streaked from a glycerol stock onto a Brain Heart Infusion (BHI) agar plate (3.7\% w/v BHI bouillon, $1.5 \% \mathrm{w} / \mathrm{v}$ agar), was grown overnight at $37^{\circ} \mathrm{C}$, and subsequently was used to inoculate $40 \mathrm{~mL}$ of $3.7 \% \mathrm{w} / \mathrm{v}$ BHI bouillon without any antibiotics in $100-\mathrm{mL}$ flasks. Fresh cells were harvested by means of centrifugation and were washed twice with $10-\mathrm{mM}$ sodium phosphate buffer ( $\mathrm{pH} 7.2$ ). The optical density was adjusted with $3.7 \% \mathrm{w} / \mathrm{v}$ BHI bouillon to $10^{4}$ cells $/ \mathrm{mL}$. For antibacterial testing, a single pin coated with $\mathrm{rHu} \beta \mathrm{D} 2$ was incubated in one well of a microtiter plate containing $100 \mu \mathrm{L}$ of the bacterial suspension.

Functionalized titanium pins without $\mathrm{rHu} \beta \mathrm{D} 2$ served as negative controls (SAM1-n, SAM2-n, SAM3-n, SAM4::Col-NHS-n, SAM4::Col-Glu-n). In addition, five independent control reactions consisting of $\mathrm{rHu} \beta \mathrm{D} 2$ in a final amount of $0 \mu \mathrm{g}$ (NC), $0.02 \mu \mathrm{g}$ (PC1), $0.2 \mu \mathrm{g}$ (PC2), $2 \mu \mathrm{g}$ (PC3), and $10 \mu \mathrm{g}$ (PC4) were examined in parallel. To determine the specificity of the antibacterial activity of $\mathrm{rHu} \beta \mathrm{D} 2,10 \mu \mathrm{L}$ of polyclonal monospecific anti-rHußD2 antibodies $(10 \mu \mathrm{g} / \mathrm{mL}$ in PBS) were co-incubated with $10 \mu \mathrm{g}$ of $\mathrm{rHu} \beta \mathrm{D} 2$ and bacterial cells (PC4/ab) (Table I).

A single microtiter plate for each experiment, including the control reaction and the five different functionalized pins, was incubated for two hours at $37^{\circ} \mathrm{C}$. The kinetic studies were performed by replacing the bacterial suspension, after two hours of cultivation, with a freshly precultured Escherichia coli solution, which contained the same bacterial concentration, and cultivating for another two hours, and so on. Colony-forming units (CFU) were determined after plating $100 \mu \mathrm{L}$ of a 1:100 dilution of the bacterial suspension on Petri dishes with BHI medium and incubating them overnight at $37^{\circ} \mathrm{C}$. For every group of the functionalized titanium pins and the controls, five independent antibacterial experiments were performed. A control (NC) of bacterial growth was examined for every independent assay. The number of colony-forming units on the control (consisting of a single Petri dish) was set to $0 \%$ bactericidal activity. The reduction in the colony-forming units resulting from the antibacterial activity of $\mathrm{rHu} \beta \mathrm{D} 2$ was related to the absolute colony-forming units of the control within every independent assay. This value, given as a percentage of the bacterial "killing" activity, was used to describe the antibacterial activity. Normalization of the antibacterial data was performed for every experimental group.

\section{Quantification of rHußD2 with ELISA}

In a parallel reaction, the amount of $\mathrm{rHu} \beta \mathrm{D} 2$ released into the $\mathrm{BHI}$ medium was determined by means of an enzyme-linked immunosorbent assay (ELISA). BHI medium was prepared as described above without bacterial cells. Titanium pins were incubated in the $\mathrm{BHI}$ medium for two hours at $37^{\circ} \mathrm{C}$, corresponding to the antibacterial assay. The same set of controls was examined as described above. Microtiter plates were coated with $50 \mu \mathrm{L}$ of polyclonal monospecific rabbit anti$\mathrm{rHu} \beta \mathrm{D} 2$ antibodies $(100 \mathrm{ng} / \mathrm{mL})$ in $0.05-\mathrm{M} \mathrm{Na}_{2} \mathrm{CO}_{3}(\mathrm{pH} 9.6)$ and then were blocked with $0.5 \%$ BSA in PBS for two hours at $37^{\circ} \mathrm{C}$. After each step, the wells were washed three times with PBS ( $\mathrm{pH} 7.4$ ) containing $0.1 \% \mathrm{v} / \mathrm{v}$ Tween 20 . Fifty microliters of the sample, consisting of BHI medium that contained either the titanium pins or the control reactions, diluted in PBS $/ 0.1 \% \mathrm{v} / \mathrm{v}$ Tween 20 , was added in duplicate and incubated for sixty minutes at $37^{\circ} \mathrm{C}$. After washing, $50 \mu \mathrm{L}$ of the rabbit biotinylated anti-rHuß $\beta 2$ antibody $(100 \mathrm{ng} / \mathrm{mL})$ was added, followed by incubation for sixty minutes. After washing, horseradish peroxidase (HRP)-conjugated streptavidin was added and incubated for forty-five minutes at $37^{\circ} \mathrm{C}$. Finally, the reaction was visualized by adding $50 \mu \mathrm{L}$ of tetramethylbenzidine (TMB) substrate for ten to twenty minutes. The reaction was stopped with $0.5-\mathrm{M} \mathrm{H}_{2} \mathrm{SO}_{4}$, and the absorbance was determined at $450 \mathrm{~nm}$ with use of an ELISA plate reader. As a reference for quantification, a standard protein curve was established by a serial dilution of $\mathrm{rHu} \beta \mathrm{D} 2(45 \mathrm{pg} / \mathrm{mL}$ to $1 \mu \mathrm{g} / \mathrm{mL})$.

\section{Source of Funding}

The present study was supported by the European Union, MyJoint, FP6-NEST028861. The funds were used for staff salaries and supplies.

\section{Results}

To determine the antibacterial activity of functionalized and subsequently coated titanium surfaces, an antibacterial assay was established. The antibacterial activity data were generated by normalizing the colony-forming units of every independent assay to the control assay. The resulting percentage of the killing activity of five independent assays was averaged. Thus, the variability of the colony-forming units of the individual antibacterial assays was reduced.

The results confirmed the efficacy and the specificity of the recombinant human $\beta$-defensin-2 (rHußD2) as an antibacterial agent (Table I). The bacteria were completely killed at a concentration of $10 \mu \mathrm{g}$ of $\mathrm{rHu} \beta \mathrm{D} 2$. In contrast, the entire bactericidal activity was blocked when a specific anti-rHußD2-antibody was added to the assay. The amount of $\mathrm{rHu} \beta \mathrm{D} 2$ detected by means of ELISA in the control assays (NC, PC1 through PC4, and PC4/ab) corresponded with the amount initially applied to the anti-bacterial assay (Table I).

Titanium oxide surfaces were functionalized by selfassembled monolayers (SAM) of common silanes. In the first 
TABLE I (continued)

\begin{tabular}{|c|c|c|c|c|c|}
\hline \multicolumn{2}{|c|}{ Titanium:SAM1 } & \multicolumn{2}{|c|}{ Titanium:SAM2 } & \multicolumn{2}{|c|}{ Titanium:SAM3 } \\
\hline SAM1-n & SAM1 & SAM2-n & SAM2 & SAM3-n & SAM3 \\
\hline 0 & 10.00 & 0 & 10.00 & 0 & 10.00 \\
\hline 0 & $6.77 \pm 1.72$ & 0 & $8.05 \pm 2.14$ & 0 & $5.35 \pm 1.32$ \\
\hline 0 & $93.20 \pm 3.78$ & 0 & $95.63 \pm 4.39$ & 0 & $89.83 \pm 3.98$ \\
\hline
\end{tabular}

experiment, titanium pins functionalized by hexadecyltrimethoxysilane (SAM1), dimethoxymethyloctylsilane (SAM2), and oxidized allyltrimethoxysilane (SAM3) were coated with $10 \mu \mathrm{g}$ of $r H u ß D 2$. The SAM surfaces alone (SAM1-n, SAM2-n, SAM$3 n)$ did not exhibit any antimicrobial activity prior to coating with $\mathrm{rHu} \beta \mathrm{D} 2$ (Table I). In contrast, functionalized titanium pins coated with rHußD2 (SAM1, SAM2, SAM3) exhibited an antibacterial activity killing rate of $>90 \%$ (Table I). The biological activity of the coated titanium pins corresponded with the positive $\mathrm{rHu} \beta \mathrm{D} 2$ control (PC4) with the highest concentration $(10 \mu \mathrm{g})$ and demonstrated successful coating of the pins with $\mathrm{rHu} \beta \mathrm{D} 2$. Furthermore, the ELISA data presented in Table I confirmed (1) that coating with $\mathrm{rHu} \beta \mathrm{D} 2$ of the functionalized pins was nearly $100 \%$, (2) that biologically active rHußD2 was eluted from the pins, and (3) that the discrepancy between the amount of rHußD2 applied for coating and the amount eluted from the pins indicated a storage function of the SAM layers for $\mathrm{rHu} \beta \mathrm{D} 2$.
To examine the release behavior of $\mathrm{rHu} \beta \mathrm{D} 2$ from the different functionalized titanium pins, a time kinetic experiment was performed. As observed in the previous experiment, coating with $10 \mu \mathrm{g}$ of $\mathrm{rHu} \beta \mathrm{D} 2$ was not sufficient to achieve complete bacterial killing, so the titanium pins were coated with an excess of $\mathrm{rHu} \beta \mathrm{D} 2(80 \mu \mathrm{g})$. Thus, a high antimicrobial activity with a killing rate of $100 \%$ was observed for all SAMs after two hours of incubation in the antibacterial assay (Fig. 1). ELISA quantification revealed that, at this time point, about 74 to $79 \mu \mathrm{g}$ of $\mathrm{rHu} \beta \mathrm{D} 2$ was eluted from the different titanium pins into the medium (Table II). The time-dependent cultivation of the titanium pins was performed by incubating the same pin after the first two-hour cultivation in a freshly prepared Escherichia coli culture containing the same amount of bacteria for another two hours, and so on. After the second cultivation step (four hours), the antimicrobial activity still reached killing rates of $52 \%$ (corresponding to $0.41 \mu \mathrm{g}$ of

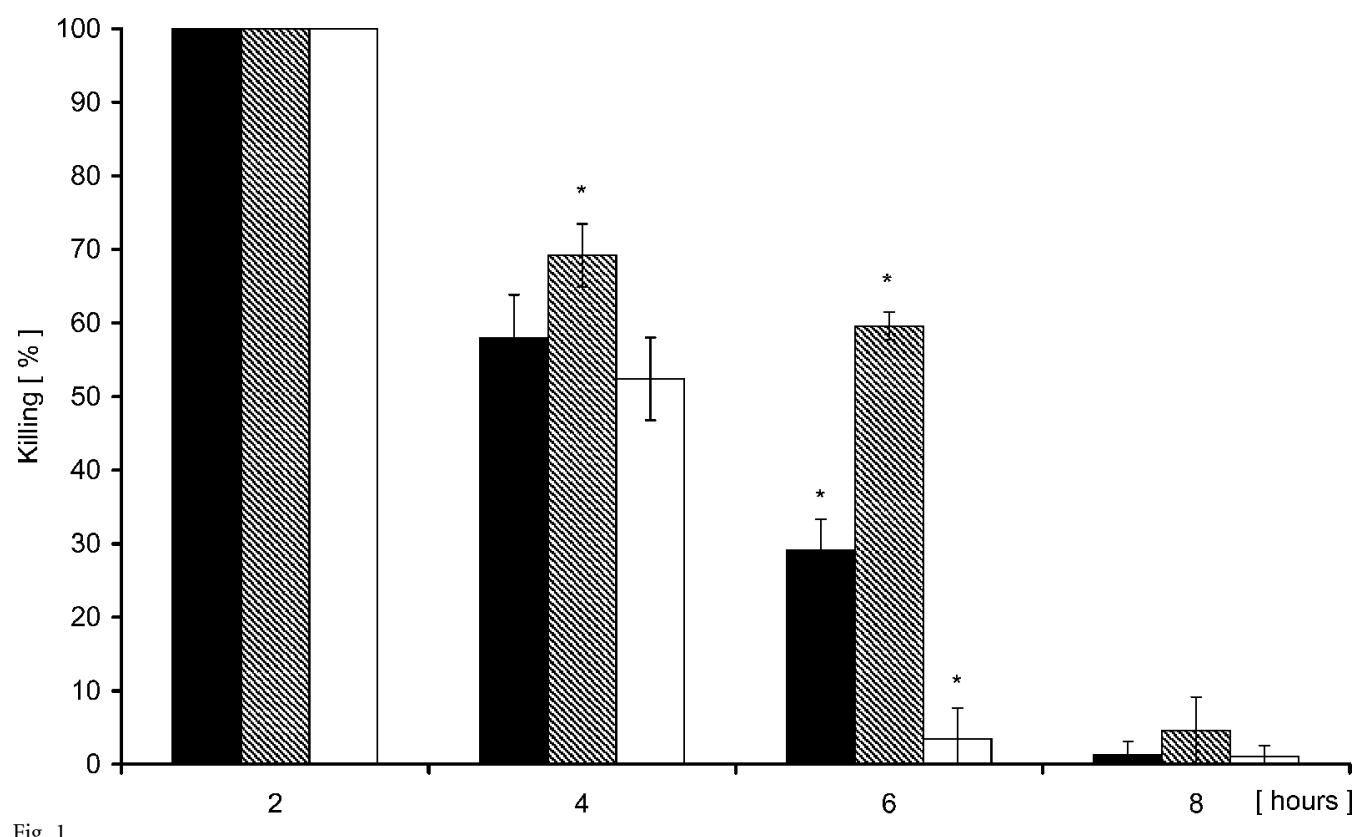

Bar graph showing the kinetics of rHußD2 release from silanized titanium surfaces as a percentage of bacteria killed. The antimicrobial activity of different silanized titanium pins coated with $80 \mu \mathrm{g}$ of rHußD2 (hexadecyltrimethoxysilane [SAM1, black bars], dimethoxymethyloctylsilane [SAM2, fasciated bars], and oxidized allyltrimethoxysilane [SAM3, white bars]) after two, four, six, and eight hours of cultivation in an Escherichia coli suspension is shown. Bacterial killing activity is shown as the mean percentage of five independent antimicrobial assays, along with the standard error of the mean. The test of significance was performed with the Student t test. An asterisk indicates a significant difference $(p<0.001)$ between groups. 
TABLE II Quantification of rHußD2 Release with ELISA*

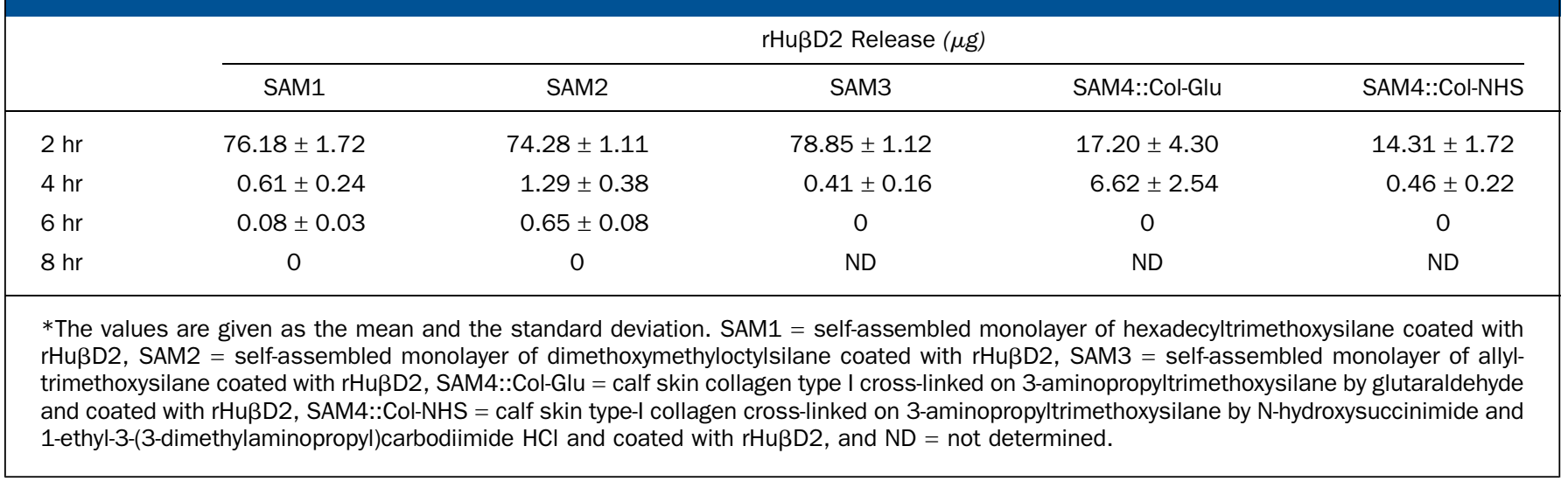

$\mathrm{rHu} \beta \mathrm{D} 2$ in the medium) to $69 \%$ (corresponding to $1.29 \mu \mathrm{g}$ of $\mathrm{rHu} \beta \mathrm{D} 2$ in the medium) (Table II). At this time point, a stronger killing activity of $\mathrm{rHu} \beta \mathrm{D} 2$ of the SAM2 pins compared with the other functionalized surfaces could be observed ( $\mathrm{p}<0.001$ ) (Fig. 1). After six hours, the killing rate for SAM2 was still $60 \%$ (corresponding to $0.65 \mu \mathrm{g}$ of $\mathrm{rHu} \beta \mathrm{D} 2$ in the medium), that for SAM1 was about $29 \%$ (corresponding to 0.08 $\mu \mathrm{g}$ of $\mathrm{rHu} \beta \mathrm{D} 2$ in the medium), and that for SAM3 dropped significantly, below $5 \%(\mathrm{p}<0.001)$ (Fig. 1). These findings indicated that different functionalized titanium pins exhibited a different elution profile in a defined time span.
As it is known that collagen has a positive impact on wound-healing, functionalized titanium pins with collagen were investigated. Two different cross-linking strategies for collagen on SAM4 were applied: (1) a covalent binding strategy with the NHS/EDC cross-linking system, and (2) the use of glutaraldehyde. Successful binding of collagen was monitored with collagen-specific DirectRed staining. Functionalized collagen titanium pins without $\mathrm{rHu} \beta \mathrm{D} 2$ did not show any antibacterial activity (Fig. 2). After two hours of incubation, pins of both cross-linking strategies generated killing rates of $100 \%$ (Fig. 2). However, ELISA quantification of these pins revealed a

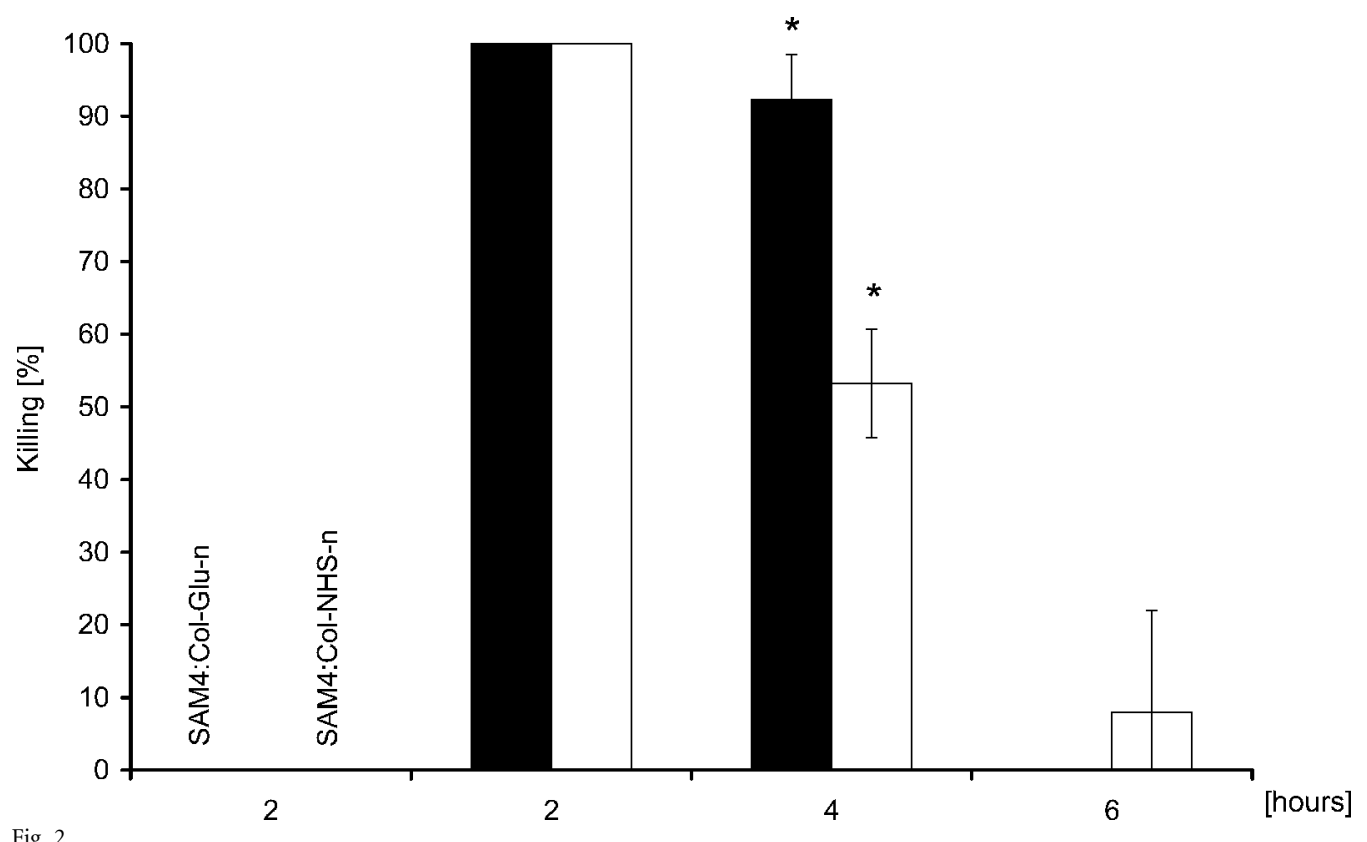

Fig. 2

Bar graph showing the antimicrobial activity of collagen titanium pins coated with $\mathrm{rHu} \beta \mathrm{D} 2$ as a percentage of bacteria killed. The antimicrobial activity of two different collagen titanium pins coated with $80 \mu \mathrm{g}$ of rHußD2 (SAM4::Col-Glu [black bars] and SAM4::Col-NHS [white bars]) after two, four, six, and eight hours of cultivation in an Escherichia coli suspension is shown. Bacterial killing activity is shown as the mean percentage of five independent antimicrobial assays, along with the standard error of the mean. The test of significance was performed with use of the Student $t$ test. An asterisk indicates a significant difference $(p<0.001)$ between groups. 
The Journal of Bone \& Joint Surgery $\cdot$ Jbjs.org Volume 93-A · Number 9 - MAY 4, 2011
Bioactive Coating of Titanium Surfaces with RHußD2 May Prevent Bacterial Colonization release of only 14 to $17 \mu \mathrm{g}$ of $\mathrm{rHu} \beta \mathrm{D} 2$ into the medium (Table II). After four hours of cultivation, the killing rate dropped to $53 \%$ (corresponding to $0.46 \mu \mathrm{g}$ of $\mathrm{rHu} \beta \mathrm{D} 2$ in the medium) for the NHS/EDC system whereas collagen pins treated with glutaraldehyde exhibited a killing rate of almost $92 \%$ (corresponding to $6.6 \mu \mathrm{g}$ of rHu$\beta \mathrm{D} 2$ in the medium). After six hours, the antimicrobial activity of both systems dropped below $10 \%$ of the killing rate and no $\mathrm{rHu} \beta \mathrm{D} 2$ was detectable in the medium with use of ELISA.

\section{Discussion}

Previous reports have shown that recombinant human $\beta$-defensin-2 (rHußD2) exhibited antibacterial activity at a minimal bactericidal concentration of $>10 \mathrm{mg} / \mathrm{L}$ against grampositive bacteria ${ }^{28,29}$ and at a minimal bactericidal concentration of $<12 \mathrm{mg} / \mathrm{L}$ against gram-negative bacteria ${ }^{25}$. These findings make $\mathrm{rHu} \beta \mathrm{D} 2$ a very good candidate as a naturally occurring antimicrobial peptide for bioactive implant coating. The antibacterial tests in the present study were performed with use of a sensitive indicator organism, Escherichia coli, in order to establish the concept of an effective antimicrobial drug delivery system using rHu $\beta \mathrm{D} 2$ on titanium surfaces. The results corroborated the efficient antibacterial activity of $\mathrm{rHu} \beta \mathrm{D} 2$ and, in addition, showed its bioactivity when coated on metallic surfaces. The present study demonstrated that titanium surfaces functionalized by different SAM (self-assembled monolayers) could store and deliver antimicrobially active rHußD2.

The aliphatic SAM layers (SAM1 and SAM2) and also the negatively charged SAM3 layer could store and release sufficient $\mathrm{rHu} \beta \mathrm{D} 2$ for antimicrobial activity in vitro (Table I). However, there were differences between the three functionalized surfaces. The $\mathrm{rHu} \beta \mathrm{D} 2$ coating exhibited continuous release of $\mathrm{rHu} \beta \mathrm{D} 2$ for several hours (Fig. 1). Hexadecyltrimethoxysilane (SAM1) and dimethoxymethyloctylsilane (SAM2) differ in the length of their exposed aliphatic chains. The aliphatic chain of dimethoxymethyloctylsilane (SAM2) is shorter and might exhibit a better $\mathrm{rHu} \beta \mathrm{D} 2$ delivery system, as indicated by an antimicrobial activity of $60 \%$ killing after three cultivation steps (six hours). The other hydrophobic layer (SAM1) exhibited a killing rate of only $29 \%$.

Both hydrophobic surfaces (SAM1 and SAM2) exhibited a higher capacity for storage and peptide release compared with the SAM3 pins (Fig.1). In addition, the functionalized SAM3 surface exhibited the fastest decrease of activity over time. After six hours, almost no killing of Escherichia coli was observed and no rHußD2 was detected with ELISA (Fig. 1 and Table II). The reason for this finding may be an ionic interaction between the SAM3 surface and $\mathrm{rHu} \beta \mathrm{D} 2$. However, excessive and unbound $\mathrm{rHu} \beta \mathrm{D} 2$ was released immediately, resulting in the delivery of most of the rHußD2 during the first two hours of cultivation.

Bacterial contamination of implants and subsequent infections often occur immediately after device implantation. Recent protocols have recommended short-term antibiotic prophylaxis ${ }^{30,31}$. The silane-functionalized titanium surfaces enable the immediate release of $\mathrm{rHu} \beta \mathrm{D} 2$ in a short time in vitro, which may prevent early postoperative infections around the implants in clinical use.

A positive effect of tissue regeneration occurred when surfaces of biomaterials were treated with collagen. Morra et al. ${ }^{32}$ reported that biochemical alteration of titanium surfaces by collagen can increase the healing rate. From this point of view, an experiment was designed to cover the titanium specimen with bovine type-I collagen prior to $\mathrm{rHu} \beta \mathrm{D} 2$ coating.

The direct comparison of collagen-treated surfaces and pure silane monolayers revealed that less $\mathrm{rHu} \beta \mathrm{D} 2$ was eluted into the medium from collagen pins (Table II). This effect might be associated with a strong and irreversible binding of $\mathrm{rHu} \beta \mathrm{D} 2$ onto the collagen matrix. Within the first two hours of the antibacterial assay of the collagen titanium pins, only 14 to $17 \mu \mathrm{g}$ of $\mathrm{rHu} \beta \mathrm{D} 2$ was detected with ELISA, which led to a complete killing of the bacteria. However, after the second cultivation step (four hours), a significant difference was observed between $\mathrm{rHu} \mathrm{BD} 2$ release from the glutaraldehyde cross-linked collagen surface (SAM4:: Col-Glu) and the other collagen surface (SAM4::Col-NHS) (Table II and Fig. 2) (p < 0.001). SAM4::Col-Glu delivered about $6.6 \mu \mathrm{g}$ of $\mathrm{rHu} \beta \mathrm{D} 2$ and caused $92 \%$ of bacterial killing. In contrast, SAM4::Col-NHS released only $0.46 \mu \mathrm{g}$ of $\mathrm{rHu} \beta \mathrm{D} 2$ with an antibacterial activity of 53\% (Table II and Fig. 2).

It was not possible to determine the bioactive $\mathrm{rHu} \beta \mathrm{D} 2$ remaining in the collagen matrix, but we speculate that as a consequence of gradual collagen catabolism in the surrounding tissue in vivo, bioactive $\mathrm{rHu} \beta \mathrm{D} 2$ might be slowly released. On the basis of this hypothesis, a peptide delivery system that will yield defined antimicrobial dosages in vivo could be developed in the future by using different collagen binding systems.

Various approaches have been described for bioactive coating onto titanium surfaces ${ }^{3,10,11,33,34}$. However, most antibiotic substances are difficult to apply because of their toxicity, their putative promotion of bacterial resistances, or their lack of availability. Here, we demonstrated, for the first time, that the use of a recombinant human $\beta$-defensin- 2 as an antimicrobial substance is suitable for bioactive coating of titanium surfaces.

Future studies will be performed to investigate these types of antibacterial coatings on orthopaedic implants and their effects on osseointegration in vivo.

Nadine Y. Pfeufer

Karsten Hofmann-Peiker

Mike Mühle

Martin C. Weigel, $\mathrm{PhD}$

Michael Kleine, $\mathrm{PhD}$

Planton GmbH, Am Kiel-Kanal 44,

D-24106 Kiel, Germany.

E-mail address for M. Kleine: kleine@planton.de

Patrick H. Warnke, MD

Faculty of Health Sciences and Medicine,

Bond University,

Gold Coast, QLD, 4229, Australia 


\section{References}

1. Khosravi AD, Ahmadi F, Salmanzadeh S, Dashtbozorg A, Montazeri EA. Study of bacteria isolated from orthopedic implant infections and their antimicrobial susceptibility pattern. Res J Microbiol. 2009;4:158-63.

2. Bulla F, Filippini P. [Prosthetic joint infections by multi-drug resistant bacteria]. Infez Med. 2010;18:5-11. Italian.

3. Jose B, Antoci V Jr, Zeiger AR, Wickstrom E, Hickok NJ. Vancomycin covalently bonded to titanium beads kills Staphylococcus aureus. Chem Biol. 2005;12: $1041-8$.

4. Antunez C, Blanca-Lopez N, Torres MJ, Mayorga C, Perez-Inestrosa E, Montañez $\mathrm{MI}$, Fernandez T, Blanca M. Immediate allergic reactions to cephalosporins: evaluation of cross-reactivity with a panel of penicillins and cephalosporins. J Allergy Clin Immunol. 2006:117:404-10.

5. Dancer SJ. The problem with cephalosporins. J Antimicrob Chemother. 2001; 48:463-78.

6. Calhoun $\mathrm{JH}$, Murray $\mathrm{CK}$, Manring MM. Multidrug-resistant organisms in military wounds from Iraq and Afghanistan. Clin Orthop Relat Res. 2008;466:1356-62.

7. Necula BS, Fratila-Apachitei LE, Zaat SA, Apachitei I, Duszczyk J. In vitro antibacterial activity of porous TiO2-Ag composite layers against methicillin-resistant Staphylococcus aureus. Acta Biomater. 2009;5:3573-80.

8. Atiyeh BS, Costagliola M, Hayek SN, Dibo SA. Effect of silver on burn wound infection control and healing: review of the literature. Burns. 2007;33:139-48.

9. Klibanov AM. Permanently microbicidal materials coatings. J Mater Chem. 2007;17:2479-82.

10. Morra M, Cassinelli C, Cascardo G, Carpi A, Fini M, Giavaresi G, Giardino R. Adsorption of cationic antibacterial on collagen-coated titanium implant devices. Biomed Pharmacother. 2004;58:418-22.

11. Statz AR, Park JP, Chongsiriwatana NP, Barron AE, Messersmith PB. Surfaceimmobilised antimicrobial peptoids. Biofouling. 2008;24:439-48.

12. Ding B, Guan Q, Walsh JP, Boswell JS, Winter TW, Winter ES, Boyd SS, Li C, Savage PB. Correlation of the antibacterial activities of cationic peptide antibiotics and cationic steroid antibiotics. J Med Chem. 2002;45:663-9.

13. Zasloff M. Antimicrobial peptides of multicellular organisms. Nature. 2002; 415:389-95.

14. Matsuzaki K. Control of cell selectivity of antimicrobial peptides. Biochim Biophys Acta. 2009;1788:1687-92.

15. Bals R. Epithelial antimicrobial peptides in host defense against infection. Respir Res. 2000;1:141-50.

16. Brogden KA. Antimicrobial peptides: pore formers or metabolic inhibitors in bacteria? Nat Rev Microbiol. 2005;3:238-50.

17. Hancock RE, Rozek A. Role of membranes in the activities of antimicrobial cationic peptides. FEMS Microbiol Lett. 2002;206:143-9.

18. Henzler Wildman KA, Lee DK, Ramamoorthy A. Mechanism of lipid bilayer disruption by the human antimicrobial peptide, LL-37. Biochemistry. 2003;42: 6545-58.

19. Schröder JM, Harder J. Human beta-defensin-2. Int J Biochem Cell Biol. 1999; 31:645-51.
20. Yang D, Chertov O, Bykovskaia SN, Chen Q, Buffo MJ, Shogan J, Anderson M, Schröder JM, Wang JM, Howard OM, Oppenheim JJ. Beta-defensins: linking innate and adaptive immunity through dendritic and T cell CCR6. Science. 1999;286:525-8.

21. Niyonsaba F, Ogawa $\mathrm{H}$, Nagaoka I. Human beta-defensin-2 functions as a chemotactic agent for tumour necrosis factor-alpha-treated human neutrophils. Immunology. 2004;111:273-81.

22. Niyonsaba F, Iwabuchi K, Matsuda H, Ogawa H, Nagaoka I. Epithelial cellderived human beta-defensin- 2 acts as a chemotaxin for mast cells through a pertussis toxin-sensitive and phospholipase C-dependent pathway. Int Immunol. 2002;14:421-6.

23. Otte JM, Werner I, Brand S, Chromik AM, Schmitz F, Kleine M, Schmidt WE. Human beta defensin 2 promotes intestinal wound healing in vitro. J Cell Biochem. 2008;104:2286-97.

24. Ganz T. Defensins: antimicrobial peptides of innate immunity. Nat Rev Immunol. 2003;3:710-20.

25. Sahly H, Schubert S, Harder J, Kleine M, Sandvang D, Ullmann U, Schröder JM, Podschun R. Activity of human beta-defensins 2 and 3 against ESBL-producing Klebsiella strains. J Antimicrob Chemother. 2006;57:562-5.

26. Jensen JM, Pfeiffer S, Akaki T, Schröder JM, Kleine M, Neumann C, Proksch E, Brasch J. Barrier function, epidermal differentiation, and human beta-defensin 2 expression in tinea corporis. J Invest Dermatol. 2007;127:1720-7.

27. Liu Q, Ding J, Mante FK, Wunder SL, Baran GR. The role of surface functiona groups in calcium phosphate nucleation on titanium foil: a self-assembled monolayer technique. Biomaterials. 2002;23:3103-11.

28. Midorikawa K, Ouhara K, Komatsuzawa H, Kawai T, Yamada S, Fujiwara T, Yamazaki K, Sayama K, Taubman MA, Kurihara H, Hashimoto K, Sugai M. Staphylococcus aureus susceptibility to innate antimicrobial peptides, beta-defensins and CAP18, expressed by human keratinocytes. Infect Immun. 2003;71:3730-9.

29. Chen X, Niyonsaba F, Ushio H, Okuda D, Nagaoka I, Ikeda S, Okumura K, Ogawa $\mathrm{H}$. Synergistic effect of antibacterial agents human beta-defensins, cathelicidin LL-37 and lysozyme against Staphylococcus aureus and Escherichia coli. J Dermatol Sci. 2005;40:123-32.

30. Hedrick TL, Evans HL, Smith RL, McElearney ST, Schulman AS, Chong TW, Pruett TL, Sawyer RG. Can we define the ideal duration of antibiotic therapy? Surg Infect (Larchmt). 2006;7:419-32.

31. Altamimi S, Khalil A, Khalaiwi KA, Milner R, Pusic MV, Al Othman MA. Short versus standard duration antibiotic therapy for acute streptococcal pharyngitis in children. Cochrane Database Syst Rev. 2009;1:CD004872.

32. Morra M, Cassinelli C, Cascardo G, Cahalan P, Cahalan L, Fini M, Giardino R. Surface engineering of titanium by collagen immobilization. Surface characterization and in vitro and in vivo studies. Biomaterials. 2003:24:4639-54.

33. Page K, Wilson M, Parkin IP. Antimicrobial surfaces and their potential in reducing the role of the inanimate environment in the incidence of hospital-acquired infections. J Mater Chem. 2009;19:3819-31.

34. Zhang F, Zhang Z, Zhu X, Kang ET, Neoh KG. Silk-functionalized titanium surfaces for enhancing osteoblast functions and reducing bacterial adhesion. Biomaterials. 2008;29:4751-9. 